\title{
LoS eStándARES del DeRECHo INTERNACIONAL DE LOS DERECHOS HUMANOS SOBRE LOS PROYECTILES DE IMPACTO CINÉTICO APLICABLES AL ESTADO DE CHILE
}

The Standards of International Human Rights Law on Kinetic Impact Projectiles Applicable to the State of Chile

\author{
PIETRO SFERRAZZA TAIBI ${ }^{*}$ \\ Universidad Andrés Bello \\ ROCÍO SÁNCHEZ PÉREZ** \\ Universidad Andrés Bello \\ ISABEL SEVERÍN FUSTER ${ }^{* * *}$ \\ Universidad Andrés Bello
}

RESUMEN

Este trabajo analizará si el uso de proyectiles de impacto cinético por parte de Carabineros de Chile en el marco de las protestas iniciadas a partir del 18 de octubre de 2019 en Chile, cumple con los estándares normativos del Derecho internacional de los Derechos Humanos sobre el uso de la fuerza.

\section{PALABRAS CLAVE}

Proyectiles de impacto cinético, uso de la fuerza, armas menos letales

\section{ABSTRACT}

This paper will analyze whether the use of kinetic impact projectiles by the Chilean uniformed police in the framework of the protests started on October 18, 2019 in Chile, complies with the normative standards of international Human Rights Law on the use of the force.

\section{KEYWORDS}

Kinetic Impact Projectiles, Use of Force, Less Lethal Weapons

\section{Introducción}

El presente trabajo tiene por objeto analizar si el uso de las escopetas antidisturbios por parte de Carabineros de Chile (Carabineros) en el marco de las protestas sociales iniciadas a partir del 18 de octubre de 2019, cumple los estándares normativos del Derecho internacional de los Derechos Humanos sobre el uso de la fuerza. Para ello, la primera parte el estudio delimitará el contexto fáctico en que se ha producido el uso de este armamento y las consecuencias que ha producido. La segunda parte del trabajo describirá los balines o perdigones, en relación con sus características físicas, como en cuanto a los riesgos que conllevan para la integridad de las personas. En la tercera parte, se analizarán sistemáticamente los estándares del Derecho internacional de los derechos humanos aplicables a este tipo de armamento, haciéndose alusión a los estándares del sistema interamericano como a los del

\footnotetext{
* Universidad Andrés Bello, Viña del Mar, Chile. Correo electrónico: pietrosferrazza@gmail.com.

** Universidad Andrés Bello, Viña del Mar, Chile. Correo electrónico: rocio.sanchez@unab.cl.

*** Universidad Andrés Bello, Viña del Mar, Chile. Correo electrónico: isaseverin@gmail.com.
} 
sistema universal. Finalmente, en la cuarta parte del trabajo se dará cuenta de la regulación jurídica del uso de escopetas antidisturbios a nivel interno, con la finalidad de esbozar algunas conclusiones sobre su compatibilidad con los estándares internacionales y los márgenes de cumplimiento en el marco de las protestas.

\section{El uso de las escopetas antidisturbios en el marco de las protestas sociales}

Desde el 18 de octubre de 2019, en Chile han tenido lugar numerosas protestas ciudadanas motivadas por una diversidad de demandas sociales, entre otras, la exigencia de nuevos canales de participación democrática; la satisfacción de derechos sociales como el derecho a la salud, a la educación y a la seguridad social; la indignación frente al abuso y la corrupción; la necesidad de iniciar un proceso constituyente y el rechazo a la indolencia de la clase política.

En el marco de dichas manifestaciones se han denunciado numerosas violaciones a los derechos fundamentales ${ }^{1}$ que han activado algunos mecanismos internacionales de protección de los sistemas interamericano y universal de derechos humanos. A nivel regional, el 12 de noviembre de 2019 la Comisión Interamericana de Derechos Humanos (CIDH) sostuvo una audiencia para analizar esta situación ${ }^{2}$. Asimismo, desde el 18 al 21 de noviembre de 2019, la $\mathrm{CIDH}$ efectuó una visita preparatoria para una visita in loco que se concretó en enero de 2020 y cuyo informe se publicará próximamente ${ }^{3}$. La CIDH también ha monitoreado este contexto emitiendo comunicados de prensa condenando las violaciones a los derechos fundamentales ${ }^{4}$.

Por su parte, la Oficina del Alto Comisionado de Naciones Unidas para los Derechos Humanos (ACNUDH) visitó Chile desde el 30 de octubre al 22 de noviembre de 2019, publicando sus resultados en un informe muy crítico hacia la actuación de las instituciones estatales en lo relativo a la tutela de los derechos fundamentales ${ }^{5}$.

La crisis social chilena también llamó la atención de importantes ONGs de derechos humanos. Tanto Amnistía Internacional (Al) como Human Rights Watch (HRW) elaboraron informes advirtiendo graves incumplimientos del Estado chileno a sus obligaciones de respeto y garantía de los derechos fundamentales ${ }^{6}$.

Ahora bien, en las manifestaciones ciudadanas las Fuerzas Armadas, de Orden y Seguridad Pública han empleado armamentos variados en el ejercicio de su facultad de uso de la fuerza. Entre tales artefactos, se ha recurrido frecuentemente al uso de las denominadas "escopetas antidisturbios", mediante las que se disparan municiones de "balines" o "perdigones". Como se explicará más adelante, estas municiones corresponden técnicamente a "proyectiles de impacto cinético" (PIC). De conformidad con el citado informe de la ACNUDH, "ha habido un uso innecesario y desproporcionado de armas menos letales, en particular escopetas antidisturbios, durante manifestaciones pacíficas y/o fuera del contexto de enfrentamientos violentos entre manifestantes y fuerzas de seguridad. Esto ha resultado en un gran número de personas heridas, incluidas transeúntes y aquellas que no cometieron actos violentos, sino que protestaron pacíficamente" ${ }^{\prime \prime}$. A raíz del elevado número de lesiones ocasionadas por estas municiones, desde los inicios de la crisis entidades como el Colegio Médico ${ }^{8}$, el Instituto Nacional de Derechos

\footnotetext{
${ }^{1}$ Según el PODER JUDICIAL (2020), p. 10, hubo un aumento significativo de juicios por violaciones a los derechos humanos entre el 18 de octubre de 2019 y el 17 de enero de 2020, en comparación con los procesos sobre dicha materia desde el 18 de octubre de 2019 al 17 de enero de 2019. ${ }^{2} \mathrm{CIDH}$ (2019b).

${ }^{3} \mathrm{CIDH}$ (2019d); CIDH (2020).

${ }^{4} \mathrm{CIDH}$ (2019a); CIDH (2019c).

${ }^{5}$ ACNUDH (2019).

${ }^{6} \mathrm{Al}$ (2019); HRW (2019).

${ }^{7}$ ACNUDH (2019), párr. 26.

8 JIMÉNEZ (2019).
} 
Humanos (INDH) ${ }^{9}$ y varios órganos del sistema de Naciones Unidas en Chile ${ }^{10}$, hicieron pública la información sobre dichas heridas y recomendaron el cese inmediato de su utilización.

Para otorgar una visión panorámica sobre la magnitud de las consecuencias generadas por el uso de las escopetas antidisturbios, resulta indispensable hacer referencia a algunos datos oficiales. En el período comprendido entre el 17 de octubre de 2019 al 18 de febrero de 2020, el INDH registró 1.681 personas heridas por disparos de perdigones y 190 por balines. Además, contabilizó 445 personas que sufrieron traumas oculares ${ }^{11}$. Asimismo, el INDH señaló que la mayoría de los casos se produjeron durante el estado de emergencia ${ }^{12}$.

En relación con la gravedad y elevada cantidad de lesiones, los informes del ACNUDH, INDH y Al sostienen que hay razones fundadas para creer que muchos de los perdigones fueron disparados desde corta distancia y hacia la parte superior del cuerpo ${ }^{13}$. Además, se utilizaron escopetas antidisturbios contra sujetos especialmente protegidos, como periodistas, defensores de derechos humanos, niñas, niños y adolescentes, personal de los servicios de salud e integrantes de la Cruz Roja Chilena ${ }^{14}$.

En noviembre de 2019 la Unidad de Trauma Ocular (UTO) del Hospital del Salvador ubicado en Santiago - centro de derivación de trauma ocular a nivel público nacional- emitió un informe examinando las consecuencias de las lesiones oculares ocasionadas por los perdigones ${ }^{15}$. De acuerdo con este estudio, ellas se explican por la gran energía con la cual el proyectil impacta la cavidad ocular o el ojo, dañando estructuras como el cristalino, la retina, las coroides y el nervio óptico ${ }^{16}$. Durante la segunda mitad de octubre y la primera semana de noviembre de 2019, la UTO analizó los casos de trauma ocular graves ocurridos en las manifestaciones, registrando la evaluación de 168 pacientes con trauma ocular severo, la mayoría provenientes de la Región Metropolitana $(86,7 \%)^{17}$. Además, identificó el mecanismo del trauma en 165 pacientes, concluyendo que en la mayoría de los casos $(80,3 \%)$ se ocasionó por el impacto de balín, tal como se explica en el gráfico de la figura 1. Estas cifras aparecen actualizadas en el Informe del INDH sobre la situación de los derechos humanos en el contexto de la crisis social, ya que la UTO remitió a dicha institución la información vigente al 3 de diciembre de 2019, en la que se da cuenta de 259 pacientes con trauma ocular ${ }^{18}$.

\footnotetext{
9 INDH (s.f.).

${ }^{10}$ NACIONES UNIDAS CHILE (2019).

${ }^{11}$ INDH (2020), p. 7.

${ }^{12}$ INDH (2019), pp. 37-38.

${ }^{13}$ ACNUDH (2019), párr. 56; INDH (2019), pp. 38-39; Al (2019).

${ }^{14}$ INDH (2019), pp. 40-41. Sobre la victimización de sujetos protegidos, véase DEFENSORÍA DE LA NIÑEZ (2019), p. 31, que registró hasta el 15 de noviembre de 2019, 43 casos de lesiones por perdigones en perjuicio de niños, niñas y adolescentes; CHVNOTICIAS (2019); 24HORAS (s.f.); T13 (2019); RADIO AGRICULTURA (2019).

${ }^{15}$ UTO (2019).

${ }^{16}$ UTO (2019), p. 9.

${ }_{17}^{17}$ UTO (2019), p. 5. En otro estudio se puede consultar la información específica sobre el tipo de lesiones ocasionadas: RODRÍGUEZ et al. (2020), p. 4.

${ }^{18}$ INDH (2019), p. 35
} 


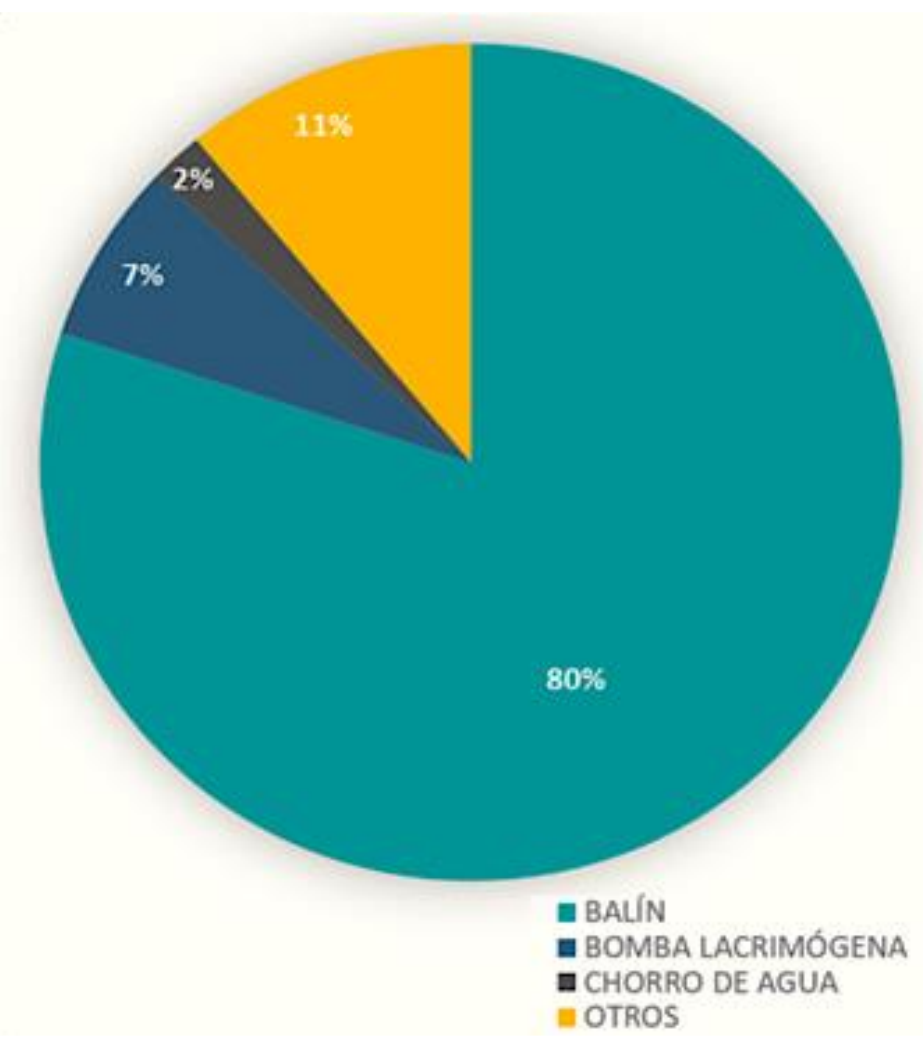

Figura 1: mecanismo del trauma ocular ${ }^{19}$

Para identificar la composición física de los perdigones, la UTO solicitó un análisis científico a la Facultad de Ciencias Físicas y Matemáticas de la Universidad de Chile (FCFM), específicamente al Departamento de Ingeniería Mecánica, el que publicó un informe el 15 de noviembre de 2019. Para tal efecto, la UTO envió dos muestras de proyectiles extraídos del organismo de pacientes afectados por su impacto ${ }^{20}$. Tras la aplicación de diferentes pruebas científicas sobre las muestras ${ }^{21}$, se concluyó que:

1. Los perdigones analizados contenían solo un $20 \%$ de caucho, mientras que el $80 \%$ restante correspondía a otros compuestos, específicamente sílice (SiO2), sulfato de bario $(\mathrm{BaSO} 4)$ y plomo $(\mathrm{Pb})$.

2. La dureza del perdigón era de 96.5 Shore $\mathrm{A}^{22}$, o sea, una dureza similar a la de un casco de construcción ${ }^{23}$.

Estas conclusiones fueron reveladoras, porque el Gobierno y Carabineros afirmaban que los perdigones eran de goma y no contenían metales ${ }^{24}$. Incluso, tras la difusión del informe de la Universidad de Chile, Carabineros continuó sosteniendo esta tesis, invocando lo informado por el proveedor, aunque comunicó que pediría a este otro análisis de las municiones ${ }^{25}$. Posteriormente, el 19 de noviembre de 2019 el General Director de la institución Mario Rozas anunció que un informe del Laboratorio de Criminalística del mismo organismo comprobó que la composición de los balines no correspondía a lo descrito por el proveedor y dispuso la

\footnotetext{
${ }^{19}$ UTO (2019), p. 6.

${ }^{20}$ FCFM (2019), p. 3.

${ }^{21}$ FCFM (2019), pp. 6-16.

22 FCFM (2019), p. 17. Estas conclusiones fueron confirmadas por otros estudios: INSTITUTO DE CIENCIAS DE LA TIERRAUNIVERSIDAD AUSTRAL DE CHILE (2019), p. 3; COX et al. (2019), p. 14.

${ }^{23}$ DEPARTAMENTO DE INGENIERÍA MECÁNICA-UNIVERSIDAD DE CHILE (2019).

${ }^{24}$ Véase exposición de Mijail Bonito, asesor del Ministerio del Interior, en audiencia sobre las protestas en Chile, sostenida ante la CIDH, en CIDH (2019d); VERA (2019).

${ }^{25}$ CARABINEROS DE CHILE (2019). Véase CASEY-MASLEN et al. (2014), p. 432, quienes desaconsejan basarse únicamente en las evaluaciones de los proveedores, porque suelen ser imprecisas.
} 
suspensión del uso balines, los que solo podrían emplearse bajo el mismo estándar de las armas de fuego, esto es, para la legítima defensa ante un peligro inminente de muerte ${ }^{26}$. Pese a este anuncio, de acuerdo con lo constatado por el ACNUDH, los balines se siguieron utilizando en las manifestaciones con posterioridad ${ }^{27}$.

El 21 de noviembre de 2019, la prensa dio a conocer un peritaje del año 2012 del Departamento de Criminalística de Carabineros de Chile sobre las municiones en cuestión ${ }^{28}$. Este informe recomendaba disparar desde una distancia superior a 30 metros, apuntando hacia el tercio medio inferior del cuerpo a fin de evitar lesiones graves durante su uso y cumplir únicamente la función de dispersar a las personas. Asimismo, concluyó que solo a partir de los 30 metros de distancia los perdigones no traspasaban la madera utilizada para el estudio balístico - una lámina de 9 milímetros de espesor - indicándose que a una distancia inferior existía el riesgo una lesión ocular que podría implicar la pérdida del ojo $^{29}$. En un estudio independiente sobre las propiedades balísticas de las municiones utilizadas por Carabineros en las protestas de 2019 (cartuchos multiproyectiles con 12 perdigones de $8 \mathrm{~mm}$ de diámetro fabricados por la empresa chilena TEC Harseim), se concluyó que existe más de un $50 \%$ de riesgo de heridas oculares de utilizarse estas municiones dentro de las distancias recomendadas, extendiéndose este riesgo hasta aproximadamente 80 metros $^{30}$. Esto significa que la probabilidad de heridas oculares es muy elevada incluso a una distancia muy superior a la recomendada.

Cabe inferir de este informe que las escopetas antidisturbios no cumplen con los requerimientos técnicos mínimos de precisión y que su uso en el contexto de manifestaciones públicas tiene la potencialidad de lesionar indiscriminadamente a una cantidad indeterminada de personas, infringiendo el deber de diferenciar entre manifestantes violentos y pacíficos. Por tanto, desde el año 2012 Carabineros conocía la lesividad de los perdigones y pese a ello los utilizó durante las protestas iniciadas el 18 de octubre. De conformidad con el informe del ACNUDH, las medidas tomadas por las autoridades estatales no fueron inmediatas y efectivas para poner fin al uso de las escopetas antidisturbios, añadiendo que la acción de Carabineros podría haber evitado que las personas sufrieran heridas tan graves ${ }^{31}$.

Como último antecedente, en su respuesta al informe del ACNUDH, el Gobierno de Chile siguió sosteniendo que las municiones empleadas por las fuerzas de orden en el marco de las protestas estaban compuestas de goma, afirmaciones que, además de generar mucha preocupación, resultan incomprensibles a la luz de lo expuesto ${ }^{32}$.

\section{Caracterización de las escopetas antidisturbios y sus municiones}

En este apartado se describirá las características técnicas de las municiones de perdigones y se dará cuenta de sus riesgos lesivos. En primer lugar, las municiones que contienen balines o perdigones son un tipo de "armas menos letales". De acuerdo con lo señalado en la Guía de Derechos Humanos de Naciones Unidas sobre Armas Menos Letales para el cumplimiento de la Ley (Guía sobre Armas Menos Letales), las armas menos letales son aquellas que pueden ser utilizadas cuando el uso de la fuerza es necesario como una alternativa menos gravosa al uso de las armas de fuego o cuando el uso de estas sería ilegal ${ }^{33}$. En segundo lugar, en cuanto a las consecuencias se trata de armamento que no pretende matar o generar lesiones irreversibles,

\footnotetext{
${ }^{26}$ CNNCHILE (2019).

${ }^{27}$ ACNUDH (2019), párr. 29 y conclusión 7. También la prensa dio cuenta de casos sucedidos posteriormente a dicha suspensión: DELGADO (2019); FERNÁNDEZ y CASSINELLI (2019).

${ }^{28}$ VEIBEL (2019).

${ }^{29}$ CARABINEROS DE CHILE (2012), p. 23. Véase WYANT y HAAG (2014), pp. 103 y ss., describiendo las pruebas más confiables en la actualidad sobre PIC.

${ }^{30}$ REYNHOUT (2020), pp. 50-51.

${ }^{31}$ ACNUDH (2019), párr. 57.

32 MISIÓN PERMANENTE DE CHILE ANTE LAS NACIONES UNIDAS Y OTRAS ORGANIZACIONES INTERNACIONALES EN GINEBRA (2020), pp. 24-27.

${ }^{33}$ ACNUDH (2020), p. 1.
} 
sino efectos temporales y reversibles ${ }^{34}$. En la literatura sobre este tipo de armas, Davison incluye como elemento conceptual la necesidad de que no generen sufrimientos innecesarios, ni efectos indiscriminados ${ }^{35}$. En tercer lugar, la noción de armas menos letales engloba una diversidad de armamento y tecnologías; por ejemplo: porras y bastones, agentes químicos irritantes, camiones hidrantes, dispositivos de desorientación, armas acústicas, armas de energía dirigida y proyectiles de impacto cinético ${ }^{36}$.

En relación con la terminología con la que se suele identificar este tipo de armas, se argumenta que se diseñan con el propósito de no ocasionar la muerte o lesiones permanentes en perjuicio de las personas contra las que se emplean, aunque en la práctica no necesariamente se evita este resultado ${ }^{37}$, porque el comportamiento de cada arma y las consecuencias que ocasiona dependen de múltiples factores ${ }^{38}$.

Ahora bien, aclarado que las escopetas antidisturbios son armas menos letales, cabe señalar que las municiones de balines o perdigones que utilizan corresponden a los denominados "proyectiles de impacto cinético" (PIC). Lo definitorio de estos proyectiles consiste en la transferencia de energía cinética desde un arma hacia el cuerpo de un sujeto ${ }^{39}$. Este tipo de armamento comprende más de setenta tipos de municiones y dispositivos de lanzamiento. Asimismo, las municiones pueden ser fabricadas con diferentes materiales, como caucho, goma, plástico o metal ${ }^{40}$.

Los PIC pueden producir diversos daños a la integridad física de las personas. Uno de los estudios más completos sobre este problema fue publicado en la revista especializada $B M J$ Open. Esta investigación revisó la literatura mundialmente publicada sobre los PIC entre 1990 y 2017 y sistematizó los datos contenidos en las fuentes seleccionadas ${ }^{41}$. Además, el estudio clasificó las lesiones producidas por los PIC considerando la gravedad y el tipo de cuidado médico requerido, categorizándolas en:

1. Lesiones menores, esto es, las que se diagnostican mediante examen físico, pero no requieren atención médica profesional, por ejemplo, contusiones menores, abrasiones o esguinces.

2. Lesiones graves, es decir, las que requieren atención médica profesional. Incluyen desde laceraciones que necesitan sutura, hasta heridas penetrantes que demandan cirugía o cuidados intensivos. También comprenden casos de incapacidades permanentes y la muerte como resultado de las lesiones. Se considera aquí la ceguera, entendiéndola como ceguera legal, esto es, en un rango de "no percepción de luz"42.

En cuanto a los datos sistematizados por el estudio, en el período objeto de análisis 1990 a 2017- se contabilizaron 1931 personas lesionadas y 53 personas fallecidas. De las personas lesionadas, 300 sufrieron incapacidades permanentes $(15,5 \%$ del total de personas lesionadas). De estas últimas, 261 sufrieron lesiones oculares (13,5\% del total de personas lesionadas y $87 \%$ de las lesiones permanentes) (figura 2$)^{43}$. Este último es un dato revelador, pues demuestra que la gran mayoría de las lesiones permanentes ocasionadas por los PIC fueron lesiones oculares.

\footnotetext{
${ }^{34}$ DAVISON (2009), pp. 2-3; KAURIN (2010), p. 102.

${ }^{35}$ DAVISON (2009), p. 8.

${ }^{36}$ PHR e INCLO (2016).

37 Para la discrepancia entre intención y aplicación de las armas menos letales, véase COLEMAN (2015), pp. 195-199.

${ }^{38}$ ACNUDH (2020), p. 1. Véase DAVISON (2009), pp. 1-2 y 6; DYMOND-BASS y CORNEY (2014), pp. 36-37; KAURIN (2010), p. 102; KOPLOW (2006), pp 9-10; MASSINGHAM (2012), pp. 673-685; COLEMAN (2015), p. 191; RAPPERT (2001), pp. 71-75.

39 HAAR et al. (2017), p. 1; DYMOND-BASS y CORNEY (2014), p. 36.

40 HAAR et al. (2017), p. 1.

${ }^{41}$ HAAR et al. (2017), pp. 2-3.

42 HAAR et al. (2017), p. 3.

${ }^{43}$ HAAR et al. (2017), pp. 5-6.
} 


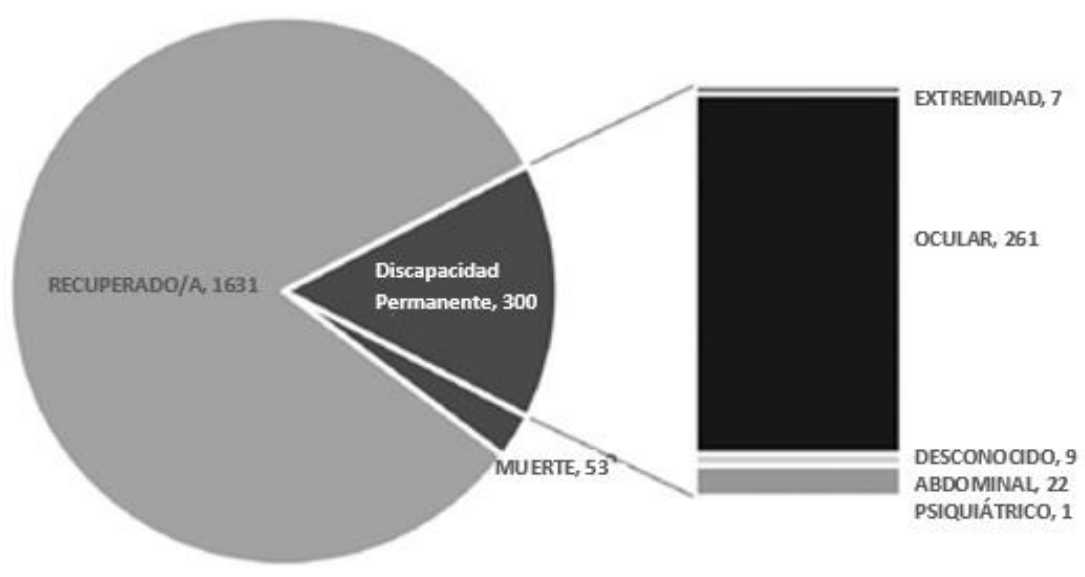

Figura 2: lesiones registradas en el estudio publicado en $B J M$ Open ${ }^{44}$

Estas cifras son sumamente interesantes en comparación con los datos del contexto chileno antes referido. En efecto, llama poderosamente la atención que el estudio publicado en BMJ Open registre una cantidad de 261 víctimas de lesiones oculares en el mundo a lo largo de veintisiete años, y en Chile casi se duplique dicho número en un período de cuatro meses.

El estudio también contiene datos desagregados que relacionan el tipo de material que componen los PIC con la naturaleza de las lesiones ocasionadas, concluyendo que la lesión de 1219 personas (63\% del total de personas lesionadas) y 237 de las incapacidades permanentes (12\% del total de personas lesionadas y $79 \%$ del total de personas con lesiones permanentes), fueron causadas por municiones cuya composición contenía algún tipo de metal ${ }^{45}$ (figura 3). Esta cifra también es llamativa, porque demuestra que los PIC que contienen metal tienen mayor grado de lesividad ${ }^{46}$.

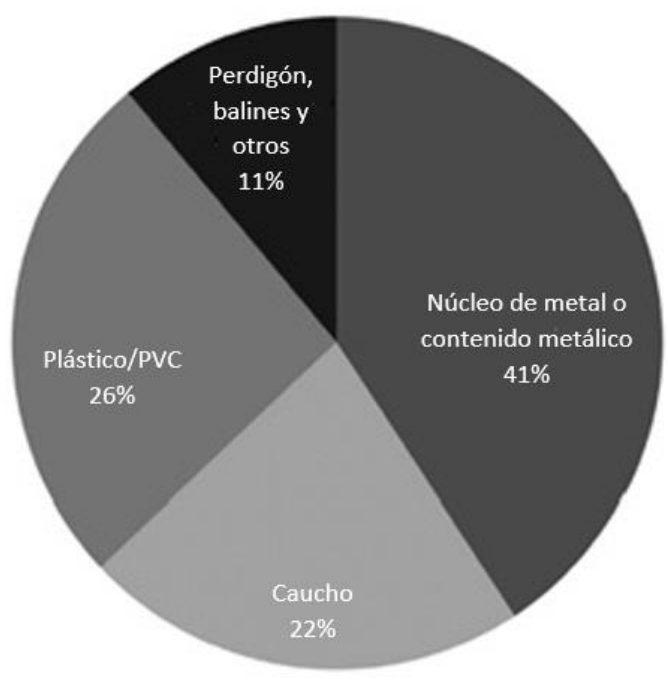

Figura 3: tipos de PIC según material ${ }^{47}$

\footnotetext{
${ }^{44}$ HAAR et al. (2017), p. 6. El idioma original del gráfico es el inglés, pero se ha hecho una traducción propia para facilitar la comprensión del lector.

${ }^{45}$ HAAR et al. (2017), pp. 6-7.

${ }^{46}$ EI COMITÉ DE DERECHOS HUMANOS (1998), párr. 17, había advertido a Israel sobre las limitaciones relacionadas con el uso de estas municiones.

${ }^{47}$ HAAR et al. (2017), p. 5. El idioma original del gráfico es el inglés, pero se ha hecho una traducción propia para facilitar la comprensión al lector.
} 


\section{Estándares del derecho internacional de los derechos humanos}

En el Derecho internacional de los derechos humanos se han desarrollado estándares sobre la limitación del uso de la fuerza por parte de los órganos estatales. Este apartado, abordará las aportaciones más relevantes del sistema interamericano, universal y europeo.

\section{El uso de la fuerza según los estándares del sistema interamericano}

Se hará referencia, en primer lugar, a la aplicabilidad de las obligaciones generales contenidas en la Convención Americana sobre Derechos Humanos (CADH) al problema del uso de la fuerza ${ }^{48}$. A continuación, se explicarán los principios sobre la limitación del uso de la fuerza desarrollados por la jurisprudencia de la Corte Interamericana de Derechos Humanos (Corte IDH). También se mencionarán los estándares desarrollados por los órganos del sistema interamericano en relación con los armamentos que pueden utilizarse en el ejercicio del uso de la fuerza.

\section{Obligaciones generales}

Cuando el Estado recurre a la fuerza debe cumplir las obligaciones generales establecidas en el art. 1 de la CADH consistentes en los deberes de respetar y garantizar. El deber de respetar exige al Estado no violar - directa o indirectamente, por acción u omisión- los derechos humanos establecidos en la $\mathrm{CADH}^{49}$. Por tanto, el Estado no debe vulnerar derechos humanos cuando recurre al uso de la fuerza.

En cambio, la obligación de garantía constriñe al Estado a "organizar todo el aparato gubernamental $y$, en general, todas las estructuras a través de las cuales se manifiesta el ejercicio del poder público, de manera tal que sean capaces de asegurar jurídicamente el libre y pleno ejercicio de los derechos humanos" ${ }^{50}$. Así, el deber de garantía implica emprender las acciones necesarias para asegurar que todas las personas sujetas a la jurisdicción del Estado estén en condiciones de ejercer los derechos humanos.

Del deber de garantía se desprenden algunos más específicos, a saber: prevenir, investigar, juzgar y, en su caso, sancionar las violaciones a los derechos consagrados en la $\mathrm{CADH}^{51}$. En consecuencia, los Estados tienen el deber de prevenir la comisión de violaciones a los derechos humanos por el uso inadecuado de la fuerza, por ejemplo, regulando su despliegue en la normativa interna o capacitando a los funcionarios facultados para ejercerla. Asimismo, si el Estado incurre en una violación a los derechos humanos a causa de un uso inadecuado de la fuerza, tiene el deber de investigar los hechos y sancionar a los autores de acreditarse su responsabilidad ${ }^{52}$.

Finalmente, el Estado debe implementar una política integral de reparaciones en beneficio de las víctimas cuyos derechos humanos fueron violados a consecuencia de un uso indebido de la fuerza. El deber del Estado y el derecho de las víctimas a la reparación está establecido en el art. 63 de la CADH. El principio de la restitutio in integrum (restitución integral) encarna la esencia de la reparación, obligando al Estado a devolver a la víctima a la situación inmediatamente anterior a la violación de sus derechos humanos $y$, de ser imposible ello, a implementar un conjunto de medidas reparatorias para enfrentar las consecuencias negativas de dicha violación ${ }^{53}$. Por tanto, si el uso de los PIC genera violaciones a los derechos humanos, las víctimas se convierten en titulares del derecho a la reparación, siendo el Estado el sujeto

\footnotetext{
${ }^{48}$ Convención Americana sobre Derechos Humanos, de 1969.

${ }^{49}$ FERRER y PELAYO (2019), p. 41.

${ }^{50}$ Corte IDH (1988), párr. 166. Véase Corte IDH (2013), párr. 223.

${ }^{51}$ Corte IDH (1988), párrs. 166 y 174; Corte IDH (2013), párr. 223.

${ }^{52}$ Corte IDH (2014b), párr. 214; Corte IDH (2014a), párr. 183.

${ }^{53}$ Corte IDH (1989), párr. 26; Corte IDH (2011), párr. 98.
} 
obligado a su satisfacción, debiendo respetar los estándares que el Derecho internacional de los derechos humanos ha desarrollado sobre la materia ${ }^{54}$.

Lo expuesto ilustra que los Estados están sujetos al cumplimiento de deberes internacionales en tres momentos: antes, durante y después del uso de la fuerza ${ }^{55}$.

\section{Principios generales que limitan el uso de la fuerza}

La jurisprudencia de la Corte IDH se ha referido a tres principios generales que limitan el uso de la fuerza en toda circunstancia.

1. Principio de legalidad, que comprende dos deberes: que los protocolos del uso de la fuerza cuenten con un marco jurídico adecuado y que el uso de la fuerza persiga un objetivo legítimo ${ }^{56}$.

2. Principio de absoluta necesidad, obligando a que el uso de la fuerza solamente proceda de no existir medios menos gravosos ${ }^{57}$.

Principio de proporcionalidad, en virtud del cual el uso de la fuerza debe ser congruente con la resistencia ofrecida y con el peligro real existente ${ }^{58}$. Así, los agentes deben aplicar un criterio de uso diferenciado y progresivo de la fuerza, determinando el grado de cooperación, resistencia o agresión por parte del sujeto al cual se pretende intervenir y emplear tácticas de negociación, control o uso de fuerza, según corresponda ${ }^{59}$.

\section{Estándares en relación con el tipo de armamento}

La Comisión Interamericana de Derechos Humanos (Comisión IDH) y la Corte IDH han señalado que los Estados deben dotar a sus agentes policiales de una diversidad de armamentos para que puedan usar la fuerza de una manera gradual ${ }^{60}$.

En relación con las armas letales, la Comisión y la Corte han indicado que su uso será legítimo, proporcional y necesario solo si es el último recurso disponible para proteger otra vida y que su empleo no será justificado cuando se busca, por ejemplo, proteger la propiedad, evitar lesiones leves o restablecer el orden público ${ }^{61}$.

Asimismo, la Comisión ha recomendado que los Estados elaboren normativas sobre las armas menos letales contemplando restricciones en atención al contexto o a los sujetos especialmente protegidos. También ha sugerido la necesidad de establecer procedimientos sancionatorios en caso de uso incorrecto ${ }^{62}$.

\section{El uso de la fuerza según los estándares del sistema universal}

En el sistema universal el problema del uso de la fuerza ha sido desarrollado por la práctica de los órganos de Naciones Unidas y ha sido abordado por relevantes instrumentos de soft law: el Código de conducta para funcionarios encargados de hacer cumplir la ley de 197963, los Principios Básicos sobre el Empleo de la Fuerza y de Armas de Fuego por los Funcionarios Encargados de Hacer Cumplir la Ley (Principios Básicos) de $1990^{64}$ y la Guía sobre Armas Menos

\footnotetext{
54 BURKE y PERSI-VICENTIC (2014), pp. 542 y ss., analizan las aportaciones del Derecho internacional sobre la reparación por violaciones a los derechos humanos cometidas mediante el uso de armas.

55 FRANCO (2017), pp. 27-28, desarrolla esta idea en relación con la afectación del derecho a la vida a consecuencia del uso de la fuerza.

${ }^{56}$ Corte IDH (2012), párrs. 80 y 85; Corte IDH (2015), párr. 265; Corte IDH (2014b), párr. 134; Corte IDH (2006), párr. 75.

${ }^{57}$ Corte IDH (2012), párr. 85; Corte IDH (2015), párr. 265; Corte IDH (2014b), párr. 126; Corte IDH (2006), párr. 67.

${ }^{58}$ Corte IDH (2012), párr. 85; Corte IDH (2015), párr. 265; Corte IDH (2014b), párr. 134.

${ }^{59}$ Corte IDH (2012), párr. 85; Corte IDH (2015), párr. 265; Corte IDH (2014b), párr. 134.

${ }^{60} \mathrm{CIDH}$ (2015), capítulo IV.A, párrs. 14-15; Corte IDH (2014b), párr. 126; Corte IDH (2012), párr. 80.

${ }^{61} \mathrm{CIDH}$ (2015), capítulo IV.A, párrs. 19; Corte IDH (2014b), párr. 131; Corte IDH (2012), párr. 84; Corte IDH (2006), párr. 68.

${ }^{62} \mathrm{CIDH}$ (2015), capítulo IV.A, párrs. 16-17.

${ }^{63}$ ASAMBLEA GENERAL ONU (1979).

${ }^{64}$ ONU (1990).
} 
Letales recientemente aprobada en agosto de $2019^{65}$. Esta Guía es un documento actual que sistematiza un conjunto de buenas prácticas sobre legalidad, diseño, producción, traslado, adquisición, prueba, entrenamiento, despliegue y utilización de armas menos letales ${ }^{66}$. En atención a su enfoque pro homine, los Estados deberían implementar sus recomendaciones, pues representan un consenso universal sobre la materia ${ }^{67}$.

Estas fuentes han especificado el contenido de los principios sobre el uso de la fuerza. Respecto del principio de precaución, las operaciones sobre uso de la fuerza deben planificarse, prepararse y llevarse a cabo, minimizado los riesgos ${ }^{68}$. Además, es imprescindible que los funcionarios autorizados para usar armamento menos letal reciban entrenamiento $y$ capacitación adecuada sobre el uso seguro del armamento y los estándares de derechos humanos ${ }^{69}$.

Además, la Guía sobre Armas Menos Letales contiene varias recomendaciones sobre el diseño, fabricación y adquisición de estos artefactos ${ }^{70}$. Una vez adquiridas, las armas deberán ser sometidas a un examen por una entidad independiente ${ }^{71}$. La información sobre sus características debe ser pública para favorecer el escrutinio público y el tratamiento médico de las lesiones que pueden ocasionar ${ }^{72}$.

La Guía también subraya la necesidad de identificar a los funcionarios encargados de hacer cumplir la ley, por ejemplo, mediante etiquetas con su nombre o número de servicio ${ }^{73}$. Respecto de las personas especialmente protegidas - niños, niñas, adolescentes, mujeres embarazadas, personas mayores, personas con discapacidad, defensoras de derechos humanos- el uso de la fuerza debe ser evitado y sujetarse a mayores resguardos ${ }^{74}$.

En relación con el principio de legalidad, la Guía exige que la legislación doméstica sea clara, difundida ampliamente para que sea accesible a todas las personas y coherente con los estándares internacionales de derechos humanos ${ }^{75}$. El uso de la fuerza solo puede perseguir el logro de un objetivo legítimo, a saber: la protección de la vida y la integridad de las personas ${ }^{76}$.

Por su parte, el estándar de necesidad obliga a que la fuerza solo se utilice cuando no exista otra alternativa razonable ${ }^{77}$. Si su uso es inevitable, debe emplearse la fuerza mínima requerida de acuerdo con las circunstancias ${ }^{78}$. En general, se prohíbe todo tipo de fuerza que tenga un efecto indiscriminado contra manifestantes pacíficos ${ }^{79}$.

En relación con el principio de proporcionalidad, debe existir un equilibrio entre la magnitud de la fuerza que se emplea y la amenaza que representa el sujeto, de manera tal que el daño infligido no sea mayor al beneficio legítimo que se persigue ${ }^{80}$.

\footnotetext{
${ }^{65}$ ACNUDH (2020). Cabe señalar que una versión no editada de este documento fue aprobada en agosto de 2019.

${ }^{66}$ ACNUDH (2020), párr. 1.3.

${ }^{67}$ Sobre la relación entre Derecho internacional y armas menos letales, véase FIDLER (2001), pp. 194-206.

${ }^{68}$ ONU (1990), principios 2, 3 y 5.b; ASAMBLEA GENERAL ONU (2017), párrs. 5 y 12.

${ }^{69}$ ACNUDH (2020), párrs. 4.5.1, 4.5.3 y 4.5.4; COMITÉ DE DERECHOS HUMANOS (2020), párr. 80; ASAMBLEA GENERAL ONU (2014), párr. 74; ASAMBLEA GENERAL ONU (2017), párrs. 13, 58, 62 y 66.

${ }^{70}$ ACNUDH (2020), párrs. 4.1, 4.2, 4.4, 4.7 y 4.8. Véase también ONU (1990), párr. 3; ASAMBLEA GENERAL ONU (2017), párr. 59.

${ }^{71}$ ONU (1990), párrs. 1 y 3; ASAMBLEA GENERAL ONU (2016), párrs. 55 y 67.c; ACNUDH (2020), párr. 4.2.2; COMITÉ DE DERECHOS HUMANOS (2020), párr. 81; ASAMBLEA GENERAL ONU (2014), párr. 76; ASAMBLEA GENERAL ONU (2017), párrs. 60 y 67. En la doctrina, véase CASEY-MASLEN et al. (2014), p. 430; KOPLOW (2006), pp. 156-159.

72 ACNUDH (2020), párr. 4.1.2.

${ }^{73}$ ACNUDH (2020), párr. 3.3. COMITÉ DE DERECHOS HUMANOS (2020), párr. 92, sujetando a ciertos estándares el recurso a funcionarios policiales de civil en manifestaciones públicas.

${ }^{74}$ ACNUDH (2020), párrs. 2.7 y 2.10.

75 ONU (1990), párr. 9; ACNUDH (2020), párr. 4.4.1; COMITÉ DE DERECHOS HUMANOS (2020), párr. 78; ASAMBLEA GENERAL ONU (2014), párrs. 57 y 63; ASAMBLEA GENERAL ONU (2017), párrs. 5, 7, 58, 62 y 65.

${ }^{76}$ ASAMBLEA GENERAL ONU (1979), art. 3.c; ACNUDH (2020), párr. 2.4; ASAMBLEA GENERAL ONU (2017), párr. 5.

${ }^{77}$ ASAMBLEA GENERAL ONU (1979), art. 3.a; ONU (1990), párr. 4; ACNUDH (2020), párrs. 2.7, 2.9; ASAMBLEA GENERAL ONU (2017), párr. 5.

78 ONU (1990), párr. 2; ACNUDH (2020), párr. 2.9

${ }^{79}$ COMITÉ DE DERECHOS HUMANOS (2020), párrs. 79, 82, 84, 87 y 88; ASAMBLEA GENERAL ONU (2017), párr. 55, refiriéndose específicamente al armamento menos letal.

${ }^{80}$ ASAMBLEA GENERAL ONU (1979), art. 3.b; ONU (1990), párr. 5.a; ACNUDH (2020), párr. 2.10; COMITÉ DE DERECHOS HUMANOS (2020), párr. 79; ASAMBLEA GENERAL ONU (2014), párr. 69; ASAMBLEA GENERAL ONU (2017), párr. 5, 10 y 11.
} 
Cabe señalar que la Guía sobre Armas Menos Letales también incluye varias recomendaciones sobre rendición de cuentas (accountability), abordando los deberes de investigar, sancionar y reparar ${ }^{81}$.

Por su parte, los Principios Básicos determinan el tipo de reuniones en que puede usarse la fuerza, distinguiendo: 1) reuniones lícitas, en las que no está autorizado el uso de la fuerza ${ }^{82}$; 2) reuniones ilícitas no violentas, en que la fuerza debe ser evitada o, si no es posible, limitada al mínimo necesario ${ }^{83}$; 3) reuniones violentas, en las que es factible el uso de la fuerza de conformidad al principio de gradualidad ${ }^{84}$. Según el Comité de Derechos Humanos, una manifestación pacífica, pero que causa una alteración del orden público, por ejemplo, mediante bloqueo del tránsito, no debe ser automáticamente dispersada a menos que la perturbación ocasionada sea seria y sostenida ${ }^{85}$.

La Guía sobre Armas Menos Letales contempla recomendaciones respecto de categorías específicas de armas menos letales, entre ellas, los PIC. Así, establece que estas municiones solo pueden emplearse para enfrentar una amenaza grave e inminente a la vida o integridad de un agente policial u otra persona ${ }^{86}$, no siendo posible recurrir a ellas para proteger derechos como la propiedad. Asimismo, especifica que su uso debe hacerse apuntando hacia las partes bajas del cuerpo ${ }^{87}$, dado que su impacto a la cara o cabeza puede provocar fracturas de cráneo, lesiones cerebrales, daños en los ojos - incluida ceguera permanente- e incluso la muerte, mientras que su impacto en las partes altas del cuerpo puede dañar órganos vitales o generar heridas penetrantes, especialmente, cuando se disparan proyectiles desde corta distancia ${ }^{88}$. También se advierte que el disparo de PIC desde posiciones elevadas podría aumentar el riesgo de impactos en la cabeza ${ }^{89}$.

La Guía establece un exigente estándar de precisión de los PIC, señalando que de dispararse desde una distancia recomendada, un proyectil no debería desviarse más allá de un diámetro de 10 centímetros del punto objetivo hacia el cual se apuntó ${ }^{90}$. Por ende, si un proyectil no cumple con este estándar, simplemente, no debería ser utilizado ${ }^{91}$. En relación con este punto, subraya la necesidad de testeos previos de los $\mathrm{PIC}^{92}$.

La Guía agrega que los proyectiles que contienen varias municiones no cumplen con los principios de necesidad y proporcionalidad. En cuanto a los PIC de metal, se proscribe su utilización, mientras que se desaconseja el empleo de municiones cuya composición contenga metal ${ }^{93}$.

Finalmente, debe resaltarse que la contravención al principio de necesidad mediante un uso innecesario o excesivo de la fuerza, puede configurar tortura o malos tratos ${ }^{94}$. El Relator Especial sobre la Tortura y otros Tratos o Penas Crueles, Inhumanos o Degradantes ha afirmado que la prohibición de estos ilícitos se aplica respecto de la violencia policial excesiva en el control de reuniones ${ }^{95}$. También ha señalado que las armas menos letales tienen la capacidad de infligir dolor o sufrimiento o coaccionar a las personas, de modo que su utilización indebida puede

\footnotetext{
${ }^{81}$ ACNUDH (2020), párrs. 3.1-3.13. Véase también COMITÉ DE DERECHOS HUMANOS (2020), párr. 90.

82 ONU (1990), párr. 12. Véase ASAMBLEA GENERAL ONU (2012), párr. 6; ASAMBLEA GENERAL ONU (2013), párr. 13; ASAMBLEA GENERAL ONU (2017), párrs. 62 y 73.

83 ONU (1990), párr. 13. Véase ASAMBLEA GENERAL ONU (2012), párr. 6.

${ }^{84}$ ONU (1990), párr. 14.

85 COMITÉ DE DERECHOS HUMANOS (2020), párr. 85.

${ }^{86}$ ACNUDH (2020), párr. 7.5.2; COMITÉ DE DERECHOS HUMANOS (2020), párr. 88.

${ }^{87}$ ACNUDH (2020), párr. 7.5.2.

${ }^{88}$ ACNUDH (2020), párr. 7.5.3.

${ }^{89}$ ACNUDH (2020), párr. 7.5.3.

${ }^{90}$ ACNUDH (2020), párr. 7.5.4.

${ }^{91}$ Según CASEY-MASLEN et al. (2014), p. 430, además de la precisión, las armas menos letales deberían satisfacer estándares de consistencia y fiabilidad, que aluden a la reproducibilidad de los atributos críticos de dos o más proyectiles idénticos entre sí.

${ }^{92}$ ACNUDH (2020), párr. 7.5.7.

${ }^{93}$ ACNUDH (2020), párrs. 7.5.6 y 7.5.8; COMITÉ DE DERECHOS HUMANOS (2020), párr. 88.

${ }^{94}$ ACNUDH (2020), párr. 2.9.

${ }^{95}$ ASAMBLEA GENERAL ONU (2017), párrs. 34 y 62
} 
infringir la prohibición de tortura y malos tratos ${ }^{96}$. De hecho, ha catalogado a los PIC como un armamento que tiene un riesgo alto de generar una infracción a esta prohibición ${ }^{97}$.

\section{El uso de la fuerza según los estándares del sistema europeo}

Siendo la finalidad de este trabajo abordar los estándares internacionales de derechos humanos, se mencionarán brevemente los desarrollados por el sistema europeo aun cuando no se apliquen en Chile.

Los estándares de este sistema provienen de la jurisprudencia del Tribunal Europeo de Derechos Humanos (TEDH), que ha señalado que todo uso de la fuerza debe adecuarse a los principios de legalidad, necesidad y proporcionalidad.

Respecto del principio de legalidad, los Estados deben contar con un marco legal ajustado al derecho internacional, que limite el empleo de la fuerza y evite accidentes, estableciendo garantías efectivas contra su uso abusivo y arbitrario ${ }^{98}$ y que además prohíba el uso de armas y municiones que produzcan consecuencias injustificadas ${ }^{99}$.

Además solo es legítimo usar la fuerza para evitar crímenes y proteger los derechos de las personas ${ }^{100}$. Por lo tanto, utilizar la fuerza para dispersar una manifestación por no cumplir las formalidades para su celebración resulta injustificado y condenable ${ }^{101}$.

Para el TEDH el estándar de necesidad en el caso del uso de la fuerza es más estricto que el aplicable a otra intervención estatal ${ }^{102}$. Solo puede usarse la fuerza ante una "necesidad imperiosa", de modo que previamente deben agotarse todos los medios que no constituyan uso de la fuerza y, siendo la fuerza el último recurso, deberá optarse por la medida que represente menor riesgo para la vida de las personas ${ }^{103}$.

El principio de proporcionalidad exige que el empleo de la fuerza atienda al contexto, al fin legítimo perseguido y a la relación entre el nivel de fuerza utilizado y el tipo de resistencia ofrecida ${ }^{104}$. Para el TEDH el uso de armas menos letales en manifestaciones supone un uso indiscriminado de la fuerza por la imposibilidad de aislar a los individuos contra quienes se pretende emplear, lo que podría constituir un trato inhumano y degradante ${ }^{105}$.

El sistema europeo ha desarrollado estándares sobre precaución del uso de la fuerza, obligando a los Estados a capacitar a las policías en prevención, auxilio a las víctimas y estándares internacionales sobre derechos humanos ${ }^{106}$ para que la decisión de emplear la fuerza considere la vida como valor fundamental ${ }^{107}$. Además, ha señalado que la policía debe abstenerse de usar la fuerza en protestas pacíficas garantizando el ejercicio del derecho de reunión ${ }^{108}$.

Por último, la investigación de todo uso de la fuerza debe ser: oportuna, o sea, sin dilaciones; independiente, esto es, excluyéndose como investigador a cualquier persona que mantenga una relación jerárquica o institucional con los implicados ${ }^{109}$; completa, es decir, incorporar toda la prueba que permita esclarecer los hechos ${ }^{110}$, entendiendo que se infringe este deber cuando las autoridades policiales no agotan todos los medios para establecer los

\footnotetext{
${ }^{96}$ ASAMBLEA GENERAL ONU (2017), párrs. 54, 57 y 62.

${ }^{97}$ ASAMBLEA GENERAL ONU (2017), párrs. 52 y 53.

98 TEDH (2011), párrs. 209 y 224; TEDH (2004), párr. 58.

99 TEDH (2017), párr. 595.

100 TEDH (2011), párr. 252; TEDH (2009), párr. 109; TEDH (2007), párr. 37.

101 TEDH (2016), párr. 80.

102 TEDH (2011), párr. 176.

103 TEDH (2011), párr. 214.

104 TEDH (2011), párr. 176.

105 TEDH (2008), párr. 111.

106 TEDH (2005b), párr. 109.

107 TEDH (2008), párr. 250; TEDH (2005a), párr. 97.

108 TEDH (2011), párr. 251; TEDH (2006), párr. 39.

109 TEDH (2001), párr. 106, señalando que no hay independencia en la práctica cuando el fiscal que investiga depende fuertemente de la información entregada por la policía implicada en el caso.

110 TEDH (2011), párr. 301.
} 
hechos o la identidad de los perpetradores ${ }^{111}$; accesible para la familia de la víctima y la sociedad civil $^{112}$; y por último, encauzada a determinar si el uso de la fuerza fue justificado ${ }^{113}$.

\section{Marco normativo nacional}

El número y tipo de lesiones por uso de PIC desde octubre de 2019 en Chile exige analizar la regulación nacional sobre la facultad de Carabineros de recurrir a la fuerza, así como la normativa específica sobre estas municiones. Se procederá a la revisión de las disposiciones pertinentes de la Constitución Política de la República ${ }^{114}$, de la Ley Orgánica Constitucional (LOC) de Carabineros de Chile № $18.691^{115}$ y de algunos cuerpos normativos administrativos, advirtiendo que estos últimos desarrollan detalladamente el uso de la fuerza.

\section{Regulación constitucional de las Fuerzas de Orden y Seguridad Pública}

La Constitución Política de la República contempla una clara diferencia funcional entre Fuerzas Armadas y Fuerzas de Orden y Seguridad, estableciendo que la función de las primeras consiste en la defensa de la seguridad nacional (art. 101 inc. 1ㅇ), mientras que el mandato de las segundas -integradas por Carabineros y Policía de Investigaciones - consiste en "dar eficacia al derecho, garantizar el orden público y la seguridad pública interior" (art. 101 inc. 2º).

\section{Regulación legal de la función de Carabineros}

La función de Carabineros como Fuerzas de Orden y Seguridad está prevista en la LOC de Carabineros de Chile № 18.691, cuyo art. 1 prescribe: "Carabineros de Chile es una institución policial técnica y de carácter militar, que integra la fuerza pública y existe para dar eficacia al derecho; su finalidad es garantizar y mantener el orden público y la seguridad pública interior en todo el territorio de la República y cumplir las demás funciones que le encomiendan la Constitución y la ley". De conformidad con en el art. 4 inc. primero y segundo de la LOC 18.691, Carabineros prestará a las autoridades judiciales y administrativas el auxilio de la fuerza pública que estas soliciten en el ejercicio de sus atribuciones.

Resulta ilustrativo aclarar el sentido de la expresión "orden público". De acuerdo con la Corte IDH, la finalidad básica de la tutela del orden público consiste en el respeto y garantía de los derechos fundamentales de las personas ${ }^{116}$. En ningún caso puede recurrirse a esta noción con la finalidad de suprimir un derecho fundamental y en el evento de que se pretenda limitar el ejercicio de un derecho por consideraciones de orden público, debe preferirse una interpretación estrictamente ceñida a las justas exigencias de una sociedad democrática ${ }^{117}$.

Esta conclusión también deriva de una interpretación sistemática y teleológica de la normativa nacional, porque la misma LOC de Carabineros establece que sus funciones deben realizarse en estricto cumplimiento de lo prescrito en la ley y la Constitución. Recuérdese que el art. 5 inciso segundo del texto constitucional sujeta el ejercicio del poder público al respeto y garantía de los derechos humanos consagrados a nivel interno e internacional ${ }^{118}$.

\section{Normas administrativas}

\footnotetext{
${ }^{111}$ TEDH (2015), párr. 52.

112 TEDH (2011), párr. 303; TEDH (2001), párr. 109.

113 TEDH (2011), párr. 301; TEDH (1999), párr. 88.

${ }^{114}$ Constitución Política de la República, de 2005.

${ }^{115}$ Ley № 18.961 , de 1990.

${ }^{116}$ Corte IDH (1986), párrs. 29-30.

${ }^{117}$ Corte IDH (1986), párr. 31; Corte IDH (1985), párr. 67.

118 ROJAS (2019).
} 
La regulación detallada del uso de la fuerza está contenida en una serie de normas administrativas que se revisarán a continuación. Se aludirá al Decreto Supremo № 1364 y a las normas que contienen los protocolos sobre el uso de las escopetas antidisturbios.

Decreto Supremo $\mathrm{N}^{\circ}$ 1364: lineamientos generales sobre uso de la fuerza

La facultad de Carabineros de recurrir al uso de la fuerza viene especificada en el Decreto Supremo $N^{\circ} 1364$ del Ministerio del Interior y Seguridad Pública de 13 de noviembre de 2018, esto es, el Reglamento que Establece disposiciones relativas al uso de la fuerza en las intervenciones policiales para el mantenimiento del orden público ${ }^{119}$. De esta normativa destaca su artículo primero, porque establece algunos lineamientos generales sobre el uso de la fuerza, a saber:

1. el deber de velar por la protección de la seguridad pública y los derechos de las personas (no 1);

2. el deber de las fuerzas policiales de respetar y cumplir la ley (no 2);

3. el deber de evitar el uso intencional de armas letales, debiendo preferir el empleo de elementos o la adopción de medidas menos dañinas para lograr sus objetivos ( $n$ - 3 );

4. la necesidad de que las normas internas que regulen la intervención policial para el mantenimiento del orden público den estricto cumplimiento a la legislación nacional y los tratados internacionales (no 8).

En el fondo, el Decreto establece algunos principios generales que favorecen la protección de los derechos de las personas, autorizando el uso de las armas letales como último recurso, y priorizando el empleo de "medidas menos dañinas", no correspondiendo necesariamente al empleo de armas menos letales, pudiendo consistir en medidas menos gravosas. Asimismo, aclara que cualquier protocolo sobre actuación de la fuerza debe cumplir no solo la ley, sino también los tratados internacionales.

\section{Protocolos específicos sobre el uso de las escopetas antidisturbios}

La utilización de las escopetas antidisturbios está regulada en dos normas administrativas que contienen los protocolos de Carabineros sobre uso de la fuerza:

1) la Circular № 1832 del Ministerio del Interior y Seguridad Pública, sobre Uso de la Fuerza; y

2) la Orden General № 2635 de Carabineros de Chile, sobre Protocolos para el Mantenimiento del Orden Público.

La elaboración de estos protocolos se realizó en cumplimiento de las medidas de reparación del caso Edmundo Alex Lemún Saavedra vs. Chile seguido ante la Comisión IDH, que concluyó con un acuerdo de cumplimiento que obliga al Estado chileno a la dictación de los reglamentos sobre el uso de la fuerza de acuerdo con los estándares internacionales de derechos humanos ${ }^{120}$. Se trata de un antecedente que ejemplifica el historial problemático de nuestro país en relación con el uso de la fuerza.

Aunque formalmente se cumplió con el establecimiento de protocolos, esta norma administrativa es evidentemente inconstitucional al infringir el principio de reserva de ley, dado que según los arts. 19 no 26 y 63 no 20 de la Constitución, la ley es la única fuente del Derecho que puede restringir el ejercicio de los derechos fundamentales ${ }^{121}$. Por ende, la autorización del uso de la fuerza supone una limitación del ejercicio de los derechos que no debe ser regulada en sede administrativa. Dicho esto, cabe destacar los aspectos más relevantes de ambos cuerpos normativos.

\footnotetext{
${ }^{119}$ Decreto Supremo № 1364, de 2018.

${ }^{120} \mathrm{CIDH}$ (2018).

${ }^{121}$ NOGUEIRA (2013), pp. 144-146.
} 


\section{Circular No 1832: la gradualidad en el uso de la fuerza}

La Circular № 1832 consagra los principios que derivan del Derecho internacional de los derechos humanos sobre el uso de la fuerza antes referidos: legalidad, necesidad, proporcionalidad y responsabilidad ${ }^{122}$. También regula el principio de gradualidad o uso diferenciado ${ }^{123}$. Así las cosas, "este enfoque gradualista se refleja en el tipo de reacción que puede aplicar la policía en el control de las personas, que varía en función de su grado de cooperación en el mantenimiento del orden público. Al respecto, la Circular distingue cinco niveles de colaboración o, en el extremo, resistencia de una persona que está siendo controlada: a mayor grado de resistencia, mayor grado de fuerza por parte de la policía"124.

\section{Orden General № 2635: uso de la fuerza en manifestaciones públicas y protocolo de uso de escopetas antidisturbios}

Carabineros solo puede recurrir al uso de la fuerza en ciertos tipos de manifestaciones. Para tal efecto, la Orden General № 2635 distingue entre manifestaciones lícitas e ilícitas. La manifestación lícita es la que se desarrolla "con tranquilidad, seguridad y respeto por el mandato de la autoridad policial, sea que cuente con la autorización previa o se trate de una actividad espontánea no autorizada"125. Por ende, habrá manifestaciones lícitas con y sin autorización de la autoridad competente. De hecho, de acuerdo con la regulación nacional del derecho de reunión contenida en el Decreto 1086, es facultad del Intendente o del Gobernador en su caso, autorizar una manifestación pública, previo aviso de los organizadores ${ }^{126}$.

Por el contrario, una manifestación ilícita puede ser violenta o agresiva. La violenta es aquella en que "se contravienen las instrucciones de la autoridad policial y los actos [de los manifestantes] involucren la vulneración de derechos de terceros, como sería la libre circulación por las vías"127. La agresiva es aquella en que "se generan daños o cuando se agrede intencionalmente a las personas o la autoridad policial" ${ }^{128}$. La Orden General autoriza el uso de la fuerza en las manifestaciones ilícitas y en las manifestaciones lícitas cuando se producen alteraciones del orden público ${ }^{129}$.

Puede inferirse que esta detallada conceptualización de las manifestaciones se realiza para identificar aquellas en que se puede recurrir al uso de la fuerza. Los tratados internacionales generales de derechos humanos - como el Pacto Internacional de Derechos Civiles y Políticos ${ }^{130}$ - cuando consagran el derecho de reunión exigen que esta se realice pacíficamente, esto es, en ausencia de violencia ${ }^{131}$. Por tanto, una reunión violenta no quedaría comprendida en el ámbito de protección de este derecho. Ahora bien, una reunión pacífica podría ser objeto de restricciones, las que: 1 ) deben imponerse de conformidad con la ley; 2) deben ser necesarias en una sociedad democrática; y 3 ) deben tener por objeto proteger una finalidad legítima, como la seguridad nacional, el orden o seguridad pública, la salud pública, la moral o los derechos de los demás ${ }^{132}$. Junto a estos requisitos, la restricción del derecho de reunión en un caso concreto debe satisfacer las exigencias del principio de proporcionalidad ${ }^{133}$.

\footnotetext{
122 Circular Núm. 1832, de 2019, p. 2. DYMOND-BASS Y CORNEY (2014), pp. 42-46.

${ }^{124}$ BLAKE et al. (2019), p. 6.

125 Orden General № 2635, de 2019, p. 7.

126 Decreto № 1086, de 1983, art. 2 letras a) y c).

127 Orden General № 2635, de 2019, p. 7.

128 Orden General № 2635, de 2019, p. 7.

129 Orden General № 2635, de 2019, pp. 8 y ss.

130 Pacto Internacional de Derechos Civiles y Políticos, de 1966.

${ }^{131}$ NOWAK (2005), pp. 486-487; WEISS (2013); DOSWALD-BECK y BELLAL (2011), p. 9.

132 NOWAK (2005), pp. 488 y ss.; WEISS (2013); DOSWALD-BECK y BELLAL (2011), p. 9.

133 NOWAK (2005), p. 491; WEISS (2013).
}

${ }^{123}$ Circular Núm. 1832, de 2019, pp. 2-3. Véase Orden General № 2635, de 2019, p. 28. Este modelo de uso de la fuerza es similar al adoptado por el NATIONAL INSTITUTE OF JUSTICE (2019) del Departamento de Justicia de Estados Unidos. Para una crítica, véase 
A la vista de este marco normativo, es plausible sostener que la fuerza podría utilizarse para enfrentar reuniones violentas o manifestaciones realizadas a pesar de una restricción que cumpla con los requerimientos señalados. Sin embargo, se necesita recordar que el uso de la fuerza siempre debe ser el último recurso y sujetarse a estándares de legalidad, necesidad y proporcionalidad estricta ${ }^{134}$.

Dicho lo anterior, la clasificación de las manifestaciones públicas en la Orden General merece algunas críticas. En primer lugar, es improcedente que se autorice el uso de la fuerza en las manifestaciones lícitas en caso de alteración al orden público, porque de producirse dichas alteraciones la manifestación se transformaría en ilícita. Así, la Orden General mantiene la posibilidad de recurrir a la fuerza incluso en manifestaciones que considera lícitas, lo que carece de sentido e infringe los estándares de los Principios Básicos de la ONU, que no permiten recurrir a la fuerza en este tipo de manifestaciones.

En segundo lugar, los criterios de la Orden General para definir las manifestaciones ilícitas violentas son demasiado amplios. Por un lado, no especifica qué se entiende por "instrucciones de la autoridad policial". Por otro lado, considera violenta toda manifestación que conlleve una vulneración de derechos de terceros. Es evidente que la realización de toda manifestación implica una restricción en el ejercicio de los derechos de terceros, pero no por ello se torna automáticamente violenta. Los derechos de terceros pueden servir de criterio para restringir el ejercicio del derecho de reunión en un caso concreto, pero es necesario valorar si se cumplen las exigencias del principio de proporcionalidad.

Pasando a otro tema, la Orden General contiene una referencia específica a las "Escopetas Antidisturbios", las que se consideran "munición no letal". Este armamento se define como "un arma de fuego larga, y su denominación de antidisturbios se debe a que utiliza cartuchos calibre $12 \mathrm{~mm}$. no letales, tales como, perdigón de goma, supersock, entre otros, utilizándose bajo el nivel 4 del uso de la fuerza"135.

Respecto de este tipo de armamento, la Orden General establece un protocolo de actuación cuyos puntos más relevantes son los siguientes:

1) El uso de estas armas debe respetar los principios generales sobre uso de la fuerza de legalidad, necesidad y proporcionalidad.

2) Solo puede recurrirse a estas armas cuando otros elementos - como el lanzamiento de agua o el uso de gases - resulten insuficientes o cuando el nivel de agresividad de las personas contra las que deberían dirigirse haga aconsejable recurrir a este armamento, únicamente para tutelar la integridad de Carabineros $u$ otras personas.

3) Este armamento solo puede ser manipulado y empleado por un usuario debidamente calificado, que debería verificar el tipo de munición que utilizará.

4) El tipo de munición debe tratarse de perdigones de goma o proyectiles super-sock. El protocolo define en un glosario al "Cartucho $12 \mathrm{~mm}$. perdigón de goma" como un "Cartucho calibre $12 \mathrm{~mm}$. el cual mantiene como proyectil 12 postas de goma endurecida, de material de caucho, el cual es de carácter no letal"136. Asimismo, se define el "cartucho $12 \mathrm{~mm}$ super-sock" como "un Cartucho de calibre $12 \mathrm{~mm}$., modelo 2581, de impacto no letal, que se compone por un saquete o bolso, una tapa de cartón del plano de boca y una vaina, que según sus datos técnicos del cartucho, el alcance efectivo es de 25 metros, el cual contiene plomo envuelto en una malla balística de kevlar"137.

5) La decisión sobre el uso de este armamento debe considerar las características del lugar, la distancia entre el tirador y la muchedumbre, y el hecho de que en esta haya sujetos especialmente protegidos (niños, niñas o adolescentes; mujeres embarazadas; personas con capacidades diferentes; adultos mayores o con notorios problemas de salud).

\footnotetext{
${ }^{134}$ CASEY-MASLEN (2014), pp. 58-59.

135 Orden General № 2635, de 2019, p. 28.

136 Orden General № 2635, de 2019, p. 28.

137 Orden General № 2635, de 2019, p. 28.
} 
6) En el evento de que un funcionario de Carabineros tomare conocimiento de haber ocasionado lesiones a una persona, deberá prestar asistencia al afectado y dar cuenta a su superior jerárquico.

Estos estándares merecen algunas observaciones críticas. Es preocupante que no exista suficiente claridad acerca del número de funcionarios certificados y capacitados para el uso de este armamento, ni sobre el tipo de entrenamiento que reciben ${ }^{138}$.

En relación con la composición de los proyectiles, lo dispuesto en la Orden General no coincide con los resultados de los peritajes científicos señalados anteriormente los que demostraron empíricamente la presencia de metal en las municiones. Además, el hecho de que cada proyectil contenga múltiples perdigones obliga al Estado a la implementación de un especial escrutinio en la evaluación de los eventuales efectos indiscriminados de este armamento $^{139}$. Por otra parte, respecto del "cartucho $12 \mathrm{~mm}$ super-sock" es preocupante que contenga plomo, considerándose el elevado grado de lesividad de los PIC que contienen metales $^{140}$. En opinión de algunos autores, los perdigones con presencia de metal infringen de manera automática los estándares de necesidad y proporcionalidad ${ }^{141}$, afirmación sobradamente suficiente para concluir su prohibición absoluta.

Ahora bien, de conformidad con esta normativa el uso de las escopetas antidisturbios puede proceder en los niveles 4 y 5 de uso autorizado de la fuerza, en los términos de la Circular № $1832^{142}$. El Nivel 4 se refiere al "uso de armas no letales" y procede ante una "agresión activa", que se produce cuando "el controlado intenta agredir al Carabinero para resistir el control o evadirlo. La amenaza no pone en riesgo vidas. Ejemplo: el controlado cierra sus puños para agredir o intenta golpear al Carabinero con un objeto"143. El Nivel 5 de uso de la fuerza autoriza el "uso de armas potencialmente letales" ante "agresión potencialmente letal", entendido como "ataque con armas o tácticas lesivas graves o potencialmente letales"144.

En atención a los riesgos para la integridad de las personas que conlleva el uso de los PIC, puede concluirse que la autorización de las escopetas antidisturbios en el Nivel 4 de cooperación vulnera, al menos, el principio de necesidad y el principio de proporcionalidad. El principio de necesidad se infringe porque las situaciones de resistencia al control de Carabineros, y de comisión de una agresión menor por parte de un sujeto, sin poner en riesgo la vida de un Carabinero, deben ser enfrentadas con medios o armamentos menos lesivos que los perdigones o balines. Por lo demás, los protocolos no especifican las nociones de resistencia al control y de agresiones que no ponen en peligro la vida.

Por su parte, el principio de proporcionalidad podría ser vulnerado en un caso concreto, porque los daños a la integridad física que pueden producir las municiones de balines o perdigones son de una magnitud sustancialmente mayor al daño que se produce en las dos hipótesis anteriores, esto es, la resistencia al control de Carabineros o una agresión que no pone en riesgo su vida.

\footnotetext{
138 RIVERA (2019); 24HORAS (2019). Sobre la necesidad de capacitación en relación con las armas menos letales, véase ACNUDH (2019), párr. 19; ASAMBLEA GENERAL ONU (2016), párr. 55; KOPLOW (2006), pp. 160-162. Véase ACNUDH (2020), párrs. 4.5.1-4.5.4, detallando los estándares internacionales sobre entrenamiento y capacitación.

${ }^{139}$ CASEY-MASLEN et al. (2014), p. 429.

${ }^{140} \mathrm{Hay}$ un caso impactante que ilustra las lesiones que puede causar esta munición. Véase MORALES (2019).

${ }^{141}$ CASEY-MASLEN et al. (2014), p. 433.

142 De acuerdo con Circular Núm. 1832, de 2019, pp. 2-3, el Nivel 1 de la Fuerza denominado "Presencia policial", consiste en el "Empleo de medios preventivos como la presencia física del Carabinero, el uso de dispositivos institucionales, o la exhibición de identificación de parte del personal de civil. Se prioriza el diálogo". Este nivel de fuerza se aplica al "Nivel 1 de cooperación" que se produce cuando "La persona sujeta a control policial da cumplimiento a las indicaciones del Carabinero sin manifestar resistencia". El Nivel 2 de fuerza denominado "Verbalización", consiste en la "Utilización de medios preventivos, como un mandato perentorio, y la persuasión". Se aplica al "Nivel 2 de resistencia pasiva", que se produce cuando "La persona sujeta a control policial no obedece las indicaciones del Carabinero y manifiesta una actitud indiferente o indolente ante la autoridad, haciendo afirmaciones corporales o verbales negativas". El Nivel 3 de fuerza, denominado "Control físico", implica la "Aplicación de medios reactivos", como la "Reducción del fiscalizado para doblegar su resistencia e inmovilizarlo". Procede en el "Nivel 3 de resistencia activa", que se genera cuando "Existe una oposición directa al control policial, que se manifiesta mediante intentos de evasión o de resistencia física". ${ }^{143}$ Circular Núm. 1832, de 2019, pp. 2-3.

${ }^{144}$ Circular Núm. 1832, de 2019, pp. 2-3.
} 


\section{Conclusiones}

En base a lo expuesto es posible enumerar las siguientes conclusiones en relación con el uso de las escopetas antidisturbios y sus municiones:

1. El tipo de municiones empleadas desde octubre de 2019 debe ser absolutamente prohibido, porque infringe relevantes estándares del Derecho interno y del Derecho internacional de los derechos humanos ${ }^{145}$.

2. Los balines contienen un elevado porcentaje de metal, lo que además de aumentar la probabilidad de lesiones graves, no están autorizado por la normativa administrativa que solo se refiere a balines de goma. De hecho, Carabineros siguió haciendo uso de estas municiones con posterioridad al informe de la Universidad de Chile que constató una presencia considerable de metales en la composición.

3. El principio de legalidad del uso de la fuerza ha sido infringido, porque la regulación de los protocolos sobre las escopetas antidisturbios está contenida en normativa administrativa y no en la ley. Esta situación también infringe el principio de reserva legal plasmado en la Constitución.

4. El principio de legalidad también ha sido vulnerado en relación con la legitimidad. En reiteradas ocasiones, los perdigones se han utilizado fuera de las hipótesis señaladas en la normativa administrativa, esto es, la tutela de la integridad de Carabineros o de otras personas. Concretamente, se han disparado para dispersar manifestaciones pacíficas, defender la propiedad privada y bienes públicos o simplemente para reprimir el ejercicio legítimo del derecho a la protesta.

5. Las escopetas antidisturbios han sido utilizadas con una frecuencia inusitada, sin haber agotado previamente otros mecanismos menos dañinos, configurándose una infracción al principio de necesidad.

6. Cabe suponer que en muchas situaciones se vulneró el principio de proporcionalidad. Aunque es un principio que debe valorarse caso a caso, debe considerarse el elevado grado de lesividad de los balines para la integridad física. El juicio de proporcionalidad exige evaluar la afectación de este derecho en el caso concreto y compararlo con el grado de satisfacción de los intereses legítimos que se persiguen cuando se recurre a las armas menos letales. Evidentemente, en todas las hipótesis en que los perdigones se utilizaron en manifestaciones pacíficas o contra sujetos especialmente protegidos, es altamente probable que la proporcionalidad resultó vulnerada.

7. Los balines vulneran el principio de distinción. Debido a sus características técnicas carecen de la precisión exigida por los estándares de Naciones Unidas, no siendo evitable la afectación indiscriminada de manifestantes pacíficos ${ }^{146}$.

8. En atención al tipo de lesiones registradas por varias entidades nacionales, entre ellas numerosas lesiones oculares, cabe concluir que no se respetaron los estándares de Naciones Unidas sobre los perdigones, pudiendo suponerse que se apuntó al torso y a la cabeza.

9. No existe información clara sobre los funcionarios de Carabineros autorizados para el uso de las escopetas ni respecto a la habilitación, entrenamiento y supervisión a la que se someten.

10. En un estudio sobre la situación del comercio y la producción de equipo concebido específicamente para someter a tortura $\mathrm{o}$ a otros tratos crueles, inhumanos $\mathrm{o}$ degradantes, el Relator Especial sobre la Cuestión de la Tortura sugirió a los Estados "Suspender la fabricación, transferencia y utilización de equipo cuyos efectos médicos no se conozcan plenamente o cuyo uso práctico haya revelado un riesgo considerable de maltrato o lesión injustificada, en espera de los resultados de una investigación

\footnotetext{
${ }^{145}$ ACNUDH (2019), recomendación № 3.

${ }^{146}$ HRW (2019).
} 
rigurosa e independiente sobre su uso"147. Esta recomendación es plenamente aplicable a las escopetas antidisturbios. En efecto, el uso de este armamento ha afectado a una ingente cantidad de víctimas ocasionándoles lesiones de extrema gravedad absolutamente injustificadas y desproporcionadas, las que eventualmente podrían configurar hipótesis de trato cruel e inhumano.

11. Carabineros utilizó balines en contra de sujetos especialmente protegidos (mujeres, niños, niñas, adolescentes, personal médico, personal de la Cruz Roja, personas mayores) y en lugares en que por sus características su uso debería estar absolutamente prohibido, como son los establecimientos educacionales.

12. El Estado de Chile debe emprender una investigación seria sobre las responsabilidades disciplinarias y penales que podrían haberse configurado como consecuencia de un uso desproporcionado de los balines ${ }^{148}$.

El Estado de Chile debe implementar una política integral de reparación en beneficio de las víctimas de PIC. Hasta el momento se ha dado a conocer un programa de recuperación para las víctimas de lesión ocular y un plan de ayuda y asistencia médica y social para lesionados graves $^{149}$. Es necesario evaluar si estos incluyen a todas las víctimas, si cumplen con los estándares del Derecho internacional y si se otorgarán otras medidas reparatorias.

\section{BIBLIOGRAFÍA CITADA}

ACNUDH (2019): "Informe sobre la misión a Chile. 30 de octubre-22 de noviembre de 2019", en: ACNUDH. Disponible en https://bit.ly/3vd1EBC [visitado el 22 de febrero de 2020].

(2020): “United Nations Human Rights Guidance on Less-Lethal Weapons in Law Enforcement", en: ACNUDH. Disponible en: https://bit.ly/3u421NE [visitado el 16 de abril de 2020].

Al (2019): “Chile: Política deliberada para dañar a manifestantes apunta a responsabilidad de mando", en: Al. Disponible en https://bit.ly/3frNqX2 [visitado el 29 de noviembre de 2019].

AMBOS, KAI (2019): "Legal Brief on the question of the existence of the contest element of crimes against humanity with regard to the events in Chile between 17 and 28 October 2019 ad described in Acusación Constitucional of 30 October 2019", en: Georg-August-Universität Göttingen. Disponible en https://bit.ly/3v2JqCO [visitado el 04 de diciembre de 2019].

AsAmblea General ONu (1979): "Código de conducta para funcionarios encargados de hacer cumplir la ley", en: ACNUDH. Disponible en https://bit.ly/3otBSXg [visitado el 16 de abril de 2020].

(2012): “Consejo de Derechos Humanos. La promoción y protección de los derechos humanos en el contexto de las manifestaciones pacíficas", en: United Nations Documents. Disponible en https://bit.ly/3v2TnQN [visitado el 16 de abril de 2020].

(2013): “Consejo de Derechos Humanos. Informe de la Alta Comisionada de las Naciones Unidas para los Derechos Humanos. Medidas efectivas y mejores prácticas para asegurar la promoción y protección de los derechos humanos en el contexto de las manifestaciones pacíficas", en: United Nations Documents. Disponible en https://bit.ly/3ymMZpO [visitado el 16 de abril de 2020].

\footnotetext{
${ }^{147}$ ECOSOC (2004), párr. 37.c.

${ }^{148}$ Considerando las cifras de personas lesionadas no debe descartarse la configuración de un patrón generalizado de violaciones a los derechos humanos que podría configurar la comisión de crímenes de lesa humanidad tipificados en la Ley № 20.357 de 2009 . Al respecto, véase MAÑALICH (2019); BASCUÑÁN (2019); AMBOS (2019), p. 17.

149 MINISTERIO DE SALUD (2019), pp. 27-33.
} 
(2014): “Informe del Relator Especial sobre las ejecuciones extrajudiciales, sumarias o arbitrarias", en: United Nations Documents. Disponible en https://bit.ly/3bBckZJ [visitado el 30 de agosto de 2020].

(2016): "Consejo de Derechos Humanos. Informe conjunto del Relator Especial sobre los derechos a la libertad de reunión pacífica y de asociación y el Relator Especial sobre las ejecuciones extrajudiciales, sumarias o arbitrarias acerca de la gestión adecuada de las manifestaciones", en: United Nations Documents. Disponible en https://bit.ly/3fODsNy [visitado el 16 de abril de 2020].

(2017): “Uso de la fuerza al margen de la detención y prohibición de la tortura y otros tratos o penas crueles, inhumanos o degradantes. Informe del Relator Especial sobre la tortura y otros tratos o penas crueles, inhumanos o degradantes", en: United Nations Documents. Disponible en https://bit.ly/3ylEdrP [visitado el 30 de agosto de 2020].

Blake, Tomás; Guiloff, Matías y Valdivia, José Miguel (2019): “Informe en Derecho. Uso de proyectiles de impacto cinético por Carabineros de Chile". Disponible en https://bit.ly/3tWPCLn [visitado el 16 de abril de 2020].

Burke, Megan y Persi-Vicentic, Loren (2014): "Remedies and reparations", en: Casey-Maslen, Stuart (Ed.), Weapons Under International Human Rights Law (Cambridge, Cambridge University Press), pp. 542-589.

CASEY-MASLEN, STUART (2014): “Crowd management, crowd control, and riot control", en: CaseyMaslen, Stuart (Ed.), Weapons Under International Human Rights Law (Cambridge, Cambridge University Press), pp. 53-79.

CASEY-MASLEN, StuART; CoRney, NeIL Y DyMOND-BASS, ABI (2014): “The Review of Weapons under International Humanitarian Law and Human Rights Law", en: Casey-Maslen, Stuart (Ed.), Weapons Under International Human Rights Law (Cambridge, Cambridge University Press), pp. 411-447.

CIDH (2009): "Informe sobre seguridad ciudadana y derechos humanos", en: CIDH. Disponible en https://bit.ly/2RvjNvV [visitado el 16 de abril de 2020].

(2015): "Informe Anual 2015", en: CIDH. Disponible en https://bit.ly/2QvPXal [visitado el 16 de abril de 2020].

(2019A): "CIDH condena excesivo uso de la fuerza y rechaza toda forma de violencia en el marco de las protestas sociales en Chile", en: CIDH. Disponible en https://bit.ly/3uONFxq [visitado el 16 de abril de 2020].

(2019B): "CIDH culmina visita preparatoria en Chile. Comunicado de prensa № 312/19, 20 de noviembre de 2019", en: CIDH. Disponible en https://bit.ly/3hyz8qk [visitado el 16 de abril de 2020].

(2019c): "CIDH condena el uso excesivo de la fuerza en el contexto de las protestas sociales en Chile, expresa su grave preocupación por el elevado número de denuncias y rechaza toda forma de violencia", en: CIDH. Disponible en https://bit.ly/3yqnBQ2 [visitado el 16 de abril de 2020].

(2019D): "CIDH sobre las protestas en Chile", en: YouTube. Disponible en https://bit.ly/3bCA6hg [visitado el 03 de diciembre de 2019].

(2020): "CIDH culmina visita in loco a Chile y presenta sus observaciones y recomendaciones preliminares", en: CIDH. Disponible en https://bit.ly/3bBIRIO [visitado el 24 de febrero de 2020]. 
Coleman, StePhen (2015): "Possible Ethical Problems with Military Use on Non-Lethal Weapons", en: Case Western Reserve Journal of International Law (Vol. 47, Issue 1), pp. 185-199.

Comité De Derechos humanos (1998): "Examen de los informes presentados por los Estados partes en virtud del artículo 40 del Pacto. Observaciones finales del Comité de Derechos Humanos. Israel", en: United Nations Documents. Disponible en https://bit.ly/3whOHa1 [visitado el 16 de abril de 2020].

Cox, Pablo; Riveros, Rodrigo; leiva, C.; Carvajal, Yuri; Fuentes P.; Recasens, Jaime; Covarrubias, Álvaro; Torres, Francisco; Ramírez, Daniel; Verdugo, Marcelo y Muñoz, Pablo (2019): “Análisis fisicoquímico de proyectiles utilizados durante las manifestaciones en Valparaíso y su correlación imagenológica con los cuerpos extraños pesquisados entre el 19 de octubre y el 15 de noviembre en el Hospital Carlos Van Buren", en: Universidad de Valparaíso. Disponible en http://bit.ly/35qkAjc [visitado el 31 de agosto de 2020].

DAVISON, NEIL (2009): 'Non-Lethal' Weapons (London, Palgrave McMillan).

DEFENSORÍA DE LA NIÑEZ (2019): "Informe situación de niños, niñas y adolescentes en el contexto de estado de emergencia y crisis social en Chile", en: Defensoría de la Niñez. Disponible en https://bit.ly/3v2cTNd [visitado el 22 de febrero de 2020].

Departamento De Ingeniería Mecánica-Universidad De Chile (2019): "Balines usados por Carabineros están compuestos en un por $80 \%$ metales y otros elementos distintos a la goma", en: Departamento de Ingeniería Mecánica-Universidad de Chile. Disponible en: https://bit.ly/3u1nRI1 [visitado el 24 de febrero de 2020].

DosWALD-BeCK, LOUISE Y BeLLAL, ANNYSSA (2011): “Evaluating the Use of Force During the Arab Spring", en: Yearbook of International Humanitarian Law (Vol. 14), pp 3-35.

DYMOND-BASS, ABI Y CORNEY, NEIL (2014): “The use of 'less-lethal' weapons in law enforcement", en: Casey-Maslen, Stuart (Ed.), Weapons Under International Human Rights Law (Cambridge, Cambridge University Press), pp. 32-52.

Ecosoc (2004): "Los derechos civiles y políticos, en particular las cuestiones relacionadas con la tortura y la detención. La tortura y otros tratos crueles, inhumanos o degradantes. Informe del Relator Especial sobre la cuestión de la tortura, Theo van Boven", en: Official Documents System of the United Nations. Disponible en https://bit.ly/33WObIG [visitado el 24 de febrero de 2020].

Ferrer, Eduardo y Pelayo, Carlos María (2019): "Artículo 1. Obligación de respetar los derechos", en Steiner, Christian y Fuchs, Marie-Christine (Eds.), Convención Americana sobre Derechos Humanos. Comentario. 2a edición (Berlín-Bogotá, Konrad Adenauer Stiftung), pp. 31-70.

FIDLER, DAVID (2001): “'Non-lethal' weapons and international law: Three perspectives on the future", en: Medicine, Conflict and Survival (Vol. 17, Issue 3), pp. 194-206.

FRANCO, MARÍA Elisa (2017): Uso de la Fuerza por parte de Agentes del Estado. Análisis desde el Derecho Internacional de los Derechos Humanos (México, Universidad Nacional Autónoma de México-Instituto de Investigaciones Jurídicas-Comisión Nacional de los Derechos Humanos).

HaAR, Rohini; IACopino, Vincent; Ranadive, NikHIL; Dandu, MadhaVI y Weiser, Sheri D. (2017): "Death, Injury and Disability from Kinetic Impact Projectiles in Crowdcontrol Settings: a Systematic Review", en: BMJ Open (Vol. 7, Issue 12), pp. 1-9.

HRW (2019): "Chile: Llamado urgente a una reforma policial tras las protestas", en: HRW. Disponible en https://bit.ly/3fJgPfJ [visitado el 29 de noviembre de 2019].

INDH (S.F.): "Archivo de reportes de estadísticas en la crisis social", en: INDH. Disponible en https://bit.ly/3u4neqB [visitado el 24 de febrero de 2020]. 
(2019): "Informe Anual sobre la situación de los derechos humanos en Chile en el contexto de la crisis social. 17 de octubre-30 de noviembre", en: INDH. Disponible en https://bit.ly/2QwpNUX [visitado el 22 de febrero de 2020].

(2020): “Reporte de datos 18 de febrero de 2020". Disponible en: https://bit.ly/3yo1adV [visitado el 24 de febrero de 2020].

instituto De Ciencias De la Tierra-Universidad Austral De Chile (2019): "Identificación de componentes de perdigones por Microscopía Electrónica de Barrido-EDX", en: Unidad de Microscopía Electrónica-Universidad Austral de Chile. Disponible en https://bit.ly/3otWXkp [visitado el 22 de febrero de 2020].

KAURIN, PAULINE (2010): "With Fear and Trembling: An Ethical Framework for Non-Lethal Weapons", en: Journal of Military Ethics (Vol. 9, № 1), pp. 100-114.

KOPLOW, DAVID (2006): Non-lethal Weapons. The Law and Policy of Revolutionary Technologies for the Military and Law Enforcement (Cambridge, Cambridge University Press).

MASSINGHAM, EVE (2012): “Conflict without Casualties... a Note of Caution: Non-Lethal Weapons and International Humanitarian Law", en: International Review of the Red Cross (Vol. 94, № 886), pp. 673-685.

MINISTERIO DE SALUD (2019): “Balance de salud en la red pública. 18 de octubre al 18 de diciembre de 2019", en: Ministerio de Salud. Disponible en: https://bit.ly/3ykuodL [visitado el 24 de febrero de 2020].

NACIONES UNIDAS CHILE (2019): "El Sistema de Naciones Unidas en Chile llama a las autoridades a terminar con el uso de proyectiles no letales", en: Naciones Unidas Chile. Disponible en https://bit.ly/3yjimkW [visitado el 26 de diciembre de 2019].

National InStitute Of Justice (2019): "The Use-of-Force Continuum", en: National Institute of Justice". Disponible en https://bit.ly/3w91jQK [visitado el 27 de diciembre de 2019].

NogueiRA, HumberTo (2013): Derechos fundamentales y garantías constitucionales. Dogmática de los derechos fundamentales, interpretación de derechos y derechos de la personalidad, 4ạ edición (Santiago, Librotecnia), tomo I.

NowaK, Manfred (2005): U.N. Covenant on Civil and Political Rights. CCPR Commentary, 2a edición (Kehl, Norbert Paul Engel Verlag).

ONU (1990): "Principios Básicos sobre el Empleo de la Fuerza y de Armas de Fuego por los Funcionarios Encargados de Hacer Cumplir la Ley", en: ACNUDH. Disponible en: https://bit.ly/3hPg0oj [visitado el 16 de abril de 2020].

PHR E INCLO (2016): "Letalidad encubierta. Efectos en la salud de las armas "menos letales" en las protestas", en: CELS. Disponible en: https://bit.ly/3hCqYOc [visitado el 21 de febrero de 2020].

PODER JUdicial (2020): "Estallido social y justicia penal”, en: Poder Judicial. Disponible en: https://bit.ly/2SSQZhi [visitado el 24 de febrero de 2020].

RAPPERT, BRIAN (2001): "Scenarios on the Future of Non-Lethal Weapons", en: Contemporary Security Policy (Vol. 22, Issue 1), pp. 57-82.

REYNHOUT, SCOTT A. (2020): "Propiedades balísticas de perdigones antidisturbios "menos letales" y su relación con trauma ocular severo en Chile", en Arsmedica. Disponible en https://bit.ly/3eYhsmg [visitado el 31 de agosto de 2020].

UTO (2019): "Informe Unidad de Trauma Ocular. Resultados preliminares obtenidos de la Unidad de Trauma Ocular 19 de octubre al 08 de noviembre de 2019", en: Sociedad Chilena de Oftalmología. Disponible en https://bit.ly/3eVJGhw [visitado el 22 de febrero de 2020]. 
WeISS, Norman (2013): "Assembly, Freedom of, International Protection", en: Oxford Public International Law. Disponible en: https://bit.ly/3uV40Fj [visitado el 18 de febrero de 2020].

WYANT, R. T. Y HAAG, LUCIEN (2014): "Less Lethal Impact Munitions: The Forensic Testing Model", en: Wyant, R. T. y Burns, Thomas (Eds.), Risk Management of less Lethal Options. Evaluation, Deployment, Aftermath and Forensics (Boca Raton, CRC Press), pp. 103-141.

\section{JURISPRUDENCIA CITADA}

CORTE IDH (1985): La colegiación obligatoria de periodistas (Arts. 13 y 29 Convención Americana sobre Derechos Humanos). Opinión Consultiva OC-5/85. 13 de noviembre de 1985. Serie A № 5.

CORTE IDH (1986): La expresión "Leyes" en el artículo 30 de la Convención Americana sobre Derechos Humanos. Opinión Consultiva OC-6/86. 9 de mayo de 1986. Serie A № 6.

CORTE IDH (1988): Velásquez Rodríguez Vs. Honduras. Fondo. 29 de julio de 1988. Serie C № 4.

CORTE IDH (1989): Velásquez Rodríguez vs. Honduras. Reparaciones y costas. 21 de julio de 1989. Serie C № 7.

TEDH (1999): Oğur V. Turkey, Judgment, Application № 21594/93, 20 de mayo 1999.

TEDH (2001): Hugh Jordan V. The United Kingdom. Judgment, Application № 24746/94, 4 de mayo de 2001.TEDH (2004): Makaratzis v. Greece. [GC], Judgment, Application № 50385/99, ECHR 2004-XI, 20 de diciembre de 2004.

TEDH (2005A): Nachova and Others V. Bulgaria. Judgment, Applications № 43577/98 and 43579/98, 6 de julio de 2005.

TEDH (2005B): Şimşek and Others V. Turkey. Judgment, Applications № 35072/97 y 37194/97, 26 de julio de 2005.

CORTE IDH (2006): Montero Aranguren y otros (Retén de Catia) Vs. Venezuela. Excepción Preliminar, Fondo, Reparaciones y Costas. 5 de julio de 2006. Serie C № 150.

TEDH (2006): Oya Ataman V. Turkey. Judgment, Application № 74552/2001, 5 de diciembre de 2006.

CORTE IDH (2007): Zambrano Vélez y otros Vs. Ecuador. Fondo, Reparaciones y Costas. 4 de julio de 2007. Serie C № 166.

TEDH (2007): Bukta and Others V. Hungary. Judgment, Application № 25691/04, 25 de septiembre de 2007.

TEDH (2008): Süleyman Çelebi and Others V. Turkey. Judgment, Application № 37273/10 y otras, 24 de agosto de 2008.

TEDH (2009): Protopapa V. Turkey. Judgment, Application № 16084/90, 24 de febrero de 2009.

CORTE IDH (2010): Cabrera García y Montiel Flores Vs. México. Excepción Preliminar, Fondo, Reparaciones y Costas. 26 de noviembre de 2010. Serie C № 220.

TEDH (2011): Giuliani and Gaggio V. Italy. [GC] Judgment, Application № 23458/02, 24 de marzo de 2011.

CORTE IDH (2011): Fontevecchia y D`Amico Vs. Argentina. Fondo, Reparaciones y Costas. 29 de noviembre de 2011. Serie C № 238.

CORTE IDH (2012): Nadege Dorzema y otros Vs. República Dominicana. Fondo, Reparaciones y Costas. 24 de octubre de 2012. Serie C № 251. 
CORTE IDH (2013): Comunidades Afrodescendientes desplazadas de la Cuenca del Río Cacarica (Operación Génesis) Vs. Colombia. Excepciones Preliminares, Fondo, Reparaciones y Costas. 20 de noviembre de 2013. Serie C № 270.

CORTE IDH (2014A): Véliz Franco y otros Vs. Guatemala. Excepciones Preliminares, Fondo, Reparaciones y Costas. 19 de mayo de 2014. Serie C № 277.

CORTE IDH (2014B): Hermanos Landaeta Mejías y otros Vs. Venezuela. Excepciones Preliminares, Fondo, Reparaciones y Costas. 27 de agosto de 2014. Serie C № 281.

CORTE IDH (2015): Cruz Sánchez y otros Vs. Perú. Excepciones Preliminares, Fondo, Reparaciones y Costas. 17 de abril de 2015. Serie C № 292.

TEDH (2015): Nagmetov V. Russia. Judgment, Application № 35589/08, 5 de noviembre de 2015. TEDH (2016): Ibrahimov and Others V. Azerbaijan. Judgment, Applications Nos. 69234/11, 69252/11 y 69335/11, 11 de febrero de 2016.

TEDH (2017): Tagayeva and Others V. Russia. Judgment, Application № 26562/07, 13 de abril de 2017.

\section{NORMAS JURÍDICAS CITADAS}

CONSTITUCIÓN PolítICA DE LA RePÚBLICA. Diario Oficial, 22 de septiembre de 2005.

CONVENCIÓN AMERICANA SOBRE DERECHOS HUMANOS, 7 al 22 de noviembre de 1969.

CIRCULAR № 1.832, USO DE LA FUERZA: actualiza instrucciones al respecto. Diario Oficial, 1 de marzo de 2019.

DECRETO № 1086, reuniones públicas. Diario Oficial, 16 de septiembre de 1983.

DECRETO SUPREMO № 1364, establece disposiciones relativas al uso de la fuerza en las intervenciones policiales para el mantenimiento del orden público. Diario Oficial, 4 de diciembre de 2018.

LEY № 18.961, orgánica constitucional de Carabineros. Diario Oficial, 7 de marzo de 1990.

LEY № 20.357, tipifica crímenes de lesa humanidad y genocidio y crímenes y delitos de guerra. Diario Oficial, 18 de julio de 2009.

ORDEN GENERAL № 2635, protocolos para el mantenimiento del orden público: aprueba nuevo texto y deroga normativa que indica. Diario Oficial, 1 de marzo de 2019.

PACto Internacional de DeReChos Civiles y Políticos, 16 de diciembre de 1966. 